\title{
Preparado cardiopulmonar
}

Jarbas Jakson DINKHUYSEN*, Luiz Carlos Bento de SOUZA*, Paulo CHACCUR**, Flávio NEGER*, Francisco PAES NETO*, Antoninho Sanfins ARNONI*, Cesar Augusto CONFORTI**, José F. BISCEGLI*, Mabel M. Barros ZAMORANO*, Elisabete C. H. LEONE*, Ricardo MANRIQUE*, Paulo P. PAULISTA*, Adib D. JATENE***, São Paulo, SP.

DINKHUYSEN, J. J.; SOUZA, L. C. B.; CHACCUR, P.; NEGER, F.; PAES NETO, F.; ARNONI, A. S.; CONFORTI, C. A.; BISCEGLI, J. F.;ZAMORANO, M. M. B.; LEONE, E. C. H.; MANRIQUE, R.; PAULISTA, P. P.; JATENE, A. D. - Preparado cardiopulmonar. Rev. Bras. Cir. Cardiovasc. , 1 (1): 20-31, 1986.

RESUMO: Trata-se de um método de preservação do conjunto coraçâo-pulmão isolado em condrçōes fisiológicas. Após abertura do tórax, é instituída a autoperfusão ex-corpore, que se obtém pela canulação do tronco braquicefálico e veia cava superior, conectando-se a um reservatório situado a 1 metro de altura, de tal maneira que, pela contração ventricular esquerda, o sangue é impulsionado ao reservatório, retorna ao coração direito e segue as vias normais, passando pelos pulmőes, onde é oxigenado. A seguir, sem qualquer interrupção dos batimentos e da ventilação, o bloco é retirado do tórax e acondicionado no Recipiente para Conservação e Transporte do Conjunto Cardiopulmonar à temperatura normal. Foram empregados 28 cảes, com peso entre 18 e $28 \mathrm{~kg}$, tendo sido feito 8 preservaçóes, para se testar o método, e 10 preservaçōes, para transplante cardiopulmonar em 10 cães receptores. Foram monitorizados, continuamente, eletrocardiograma, pressão intraórtica, pressão ventricular esquerda, DP/DT, indice tempo-tensão e trabalho cardiaco que mostraram valores estáveis e satisfatórios, tanto na fase de preservação, quanto após o transplante. Os gases sangüineos guardaram relação com as diferentes misturas administradas à ventilação. A análise microscópica de fragmentos do músculo cardíaco e tecido pulmonar retirado ao final dos procedimentos não revelou alteraçôes significativas decorrentes do método.

DESCRITORES: preparado cardiopulmonar; transplante cardiaco.

\section{INTRODUÇĀO}

O transplante cardiaco representa uma opção terapêutica viável para um grupo selecionado de pacientes portadores de estágios finais da doença cardiaca. Desde a realização da primeira bem sucedida intervenção, em $1967^{\prime}$, observou-se extraordinário progresso nesta modalidade terapêutica, que não pode mais ser considerada como tratamento experimental. Em função dos consistentes resultados atingidos, esta operação faz parte quase que rotineira dos grandes centros de cirurgia cardiovascular.
Da mesma maneira, o transplante combinado coração-pulmão ${ }^{16}$ ampliou mais esta perspectiva, pois a sua aplicação abrange espectro maior de patologias insolúveis e terminais, como a síndrome de Einsenmenger e a hipertensão pulmonar primária.

Paralelamente a estes avanços, as técnicas de preservação de órgãos também sofreram evolução considerável, sendo possível manter a integridade do miocárdio anóxico acima de 3 horas, com a aplicação de soluções cardioplégicas e hipoter$\mathrm{mia}^{23}$, proporcionando maior elasticidade ao proce-

Trabalho realizado no Instituto Dante Pazzanese de Cardiologia, Sảo Paulo, SP, Brasil.

Apresentado ao 13: Congresso Nacional de Cirurgia Cardiaca, Sâo Paulo. SP, 4 e 5 de abril, 1986

- Do Instituto Dante Pazzanese de Cardiologia.

*. Do Instituto do Coraçåo da Associaçăo do Sanatório Sírio.

*.. Do Instituto do Coraçâo do Hospital das Clínicas da Faculdade de Medicina da Universidade de São Paulo.

Endereço para Separatas: Jarbas Dinkhuysen. Caixa Postal 215. Sảo Paulo, SP, Brasil. 
dimento e facultando a busca do órgão a grandes distâncias. Todavia, o tecido pulmonar apresenta comportamento diverso do miocárdio, sendo muito sensível a períodos mais prolongados de anóxia ${ }^{7}$ mesmo em hipotermia, o que inviabiliza a busca à distância, assim como delimita a indicaçāo de transplante, principalmente nos Serviços baseados em núcleos populacionais pequenos.

A seleção criteriosa dos receptores e doadores, preservação adequada dos órgãos, técnica cirúrgica boa, imunossupressão rigorosa e controle de infecção constituem os pontos cardiais da técnica de transplante cardíaco e cardiopulmonar.

A concepção de manter in vitro um órgão em condições fisiológicas sem adição de agentes químicos, ou físicos, como método de preservaçāo parece atrativa, porquanto as regras de manutenção fisiológica e bioquímica não sofreriam qualquer tipo de interação, fazendo pressupor, in vivo, limites confiáveis de aplicabilidade.

O primeiro preparado no qual o coração e os pulmões foram mantidos funcionantes foi descrito, no século passado, por MARTIN, $1883^{11}$

Entretanto, foram STARLING, juntamente com KNOULTON e PATTERSON ${ }^{9,13}$, no início do nosso século, que tornaram o preparado cardiopulmonar o experimento básico para pesquisas da fisiologia cardiovascular, sendo isto denominado Princípio de Starling.

Em 1956, iniciaram-se vários estudos experimentais ${ }^{21}$, visando ao emprego do preparado para fins de transplante. MATEJICEK ${ }^{12}$ usou-o para transplantar o coração junto com o lobo superior direito para tórax de outro animal; DEMIKHOV ${ }^{5}$, em um exaustivo estudo, mostrou inúmeras possíveis aplicações do princípio de Starling para transplante; todavia, não valorizou os problemas relacionados com a preservação mais prolongada, devido às dificuldades que tinha em manter pressão e volume circulante. As modificaçōes introduzidas por ROBICSEK et alii ${ }^{19}$ permitiram a manutenção da perfusão tecidual constante e o volume autoajustado, fatores fundamentais para manter, por períodos prolongados, o coração batendo e os pulmões ventilando. O mesmo autor, através de extenso estudo ${ }^{18}$ demonstrou a estabilidade hemodinâmica e metabólica do preparado por períodos superiores a 20 horas, assim como realizou transplantes ${ }^{20}$ após a preservação.

Trabalhos mais recentes demonstram que o preparado cardiopulmonar, após período de preservação, foi experimentalmente transplantado com sucesso ${ }^{6}$, assim como tem sido empregado no transplante cardiopulmonar humano, como método de procura de órgãos à distância ${ }^{8}$.
No presente trabalho, são apresentadas a técnica de obtenção do preparado, sua manutenção por períodos prolongados pela autoperfusão $e x$ corpore, com especial referência às variações hemodinâmicas, metabólicas e sua transplantabilidade.

\section{MATERIAL E MÉTODO}

Foram empregados 28 cães, com peso entre 18 e $28 \mathrm{~kg}$, mantidos sob anestesia geral com entubação endotraqueal e ventilados com pressão positiva intermitente e $\mathrm{FIO}_{2} 1,0$. O eletrocardiograma contínuo foi obtido através da colocação de derivações periféricas distribuídas nos membros do animal. Logo de início, dissecavam-se artéria e veia periféricas para controle da pressão arterial média e das dosagens bioquímicas do sangue, assim como via de administração venosa, respectivamente. Através de toracotomia mediana transesternal, obtinha-se acesso às estruturas do toráx, isolado-se as veias cavas superior e inferior, ázigos, as porções ascendente, transversa e descencende da aorta, incluindo seus troncos supraórticos e, por fim, a traquéia. Após heparinização sistêmica ( $3 \mathrm{mg}$ $\mathrm{kg}$ peso), canulava-se o tronco braquicefálico e a veia cava superior com cânulas $18 \mathrm{~F}$, conectando-as a um reservatório de plástico com 5 litros de capacidade situado a 1 metro acima do plano da valva aórtica, contendo Ringuer $500 \mathrm{ml}$ a $37^{\circ} \mathrm{C}$. Catéteres eram introduzidos na aorta ascendente, via carótida comum, para controle da pressão intraórtica e na cavidade livre do ventrículo esquerdo, através da auriculeta esquerda, para avaliação da pressão intraventricular esquerda (Quadro 1).

QUADRO 1

MATERIAL E MÉTODO

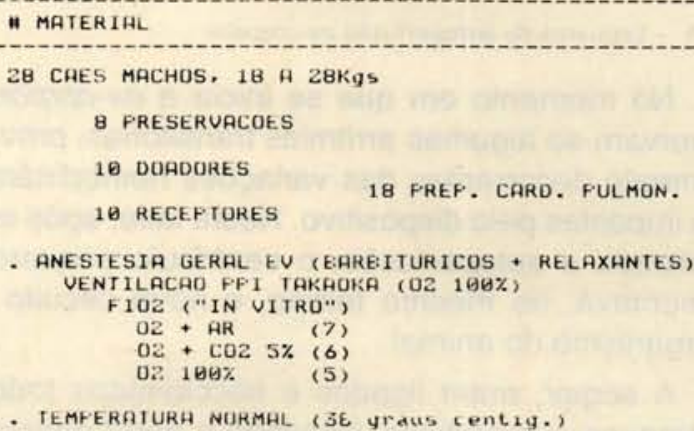

A auto-perfusāo ex-corpore era iniciada com a ejeção de sangue do ventrículo esquerdo para o reservatório e daí retornando ao coração direito e pulmões, onde era oxigenado, completando o ciclo. Estabelece-se, assim, um circuito hemodinâmico fisiológico auto-regulado: a resistência periférica (pós-carga) é dada pelo diâmetro do tubo de plástico que liga ao reservatório e pela altura da coluna líqüida $(1 \mathrm{~m})$ e as variações de volume 
circulante são absorvidas pelo reservatório, cuja capacidade, necessariamente, deve ser maios que a volemia do animal. No tubo de retorno ao átrio direito, era colocada uma pinça variável, cuja função era adequar o volume (pré-carga) que chega ao átrio direito (Figura 1).

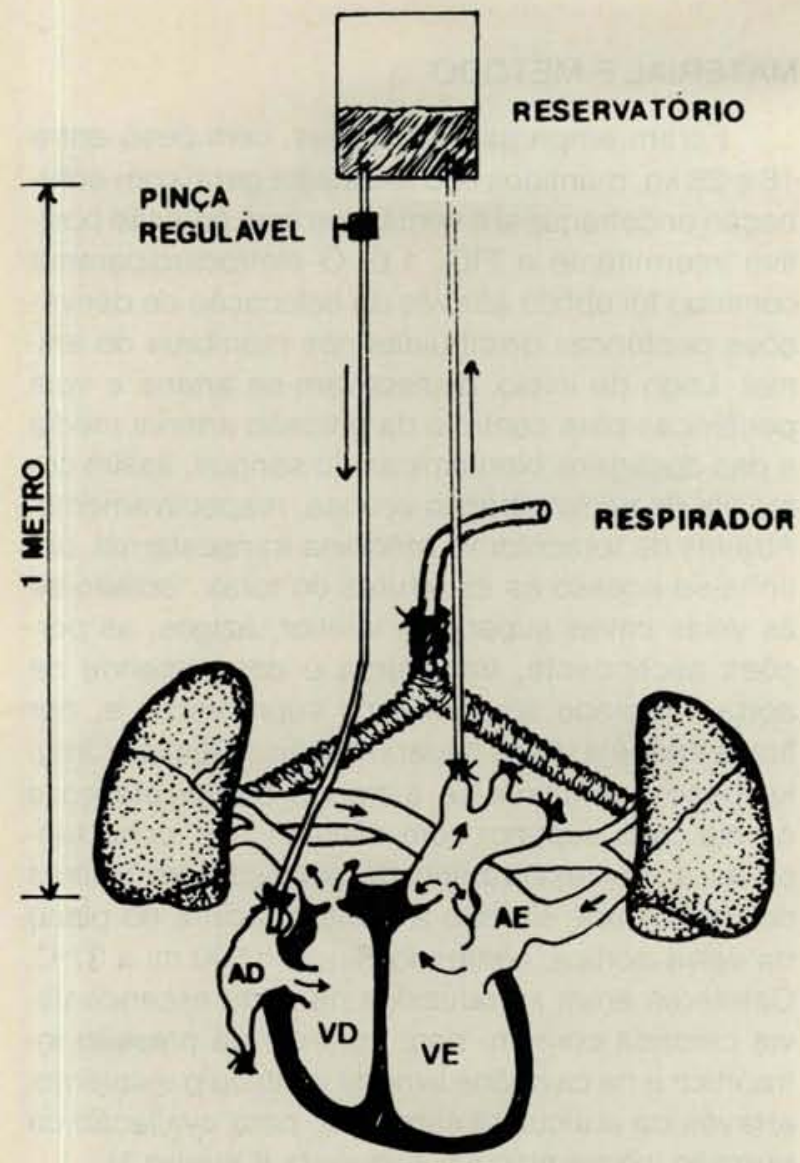

\section{AUTOPERFUSÃo "EX-CORPORE"}

IDPC SP

Fig. 1 - Esquema da autoperfusâo ex-corpore

No momento em que se inicia a ex-corpore, observam-se algumas arritmias transitórias, provavelmente decorrentes das variaçōes hemodinâmicas impostas pelo dispositivo. Nesta fase, após estabilizada a autoperfusāo, o ventrículo esquerdo alimentava, ao mesmo tempo, o novo circuito e o organismo do animal.

A seguir, eram ligados e seccionados todos os troncos supraórticos, incluindo a aorta descendente, mantendo livre a drenagem pelas cavas e ázigos, a fim de que todo o sangue que chegasse ao coração fosse desviado para o reservatório, concentrando toda a volemia. Feito isto, eram realizadas as-ligaduras destes vasos, ocasião em que era interrompida, completamente, a circulação nativa, com conseqüente falta de perfusão e de extração de consumo de oxigênio pelos tecidos do animal. A partir daí, a ventilação do preparado foi feita com $\mathrm{O}_{2}+\operatorname{Ar}$ (7 cães), $\mathrm{O}_{2}+\mathrm{CO}_{2}$ (6 cães), $\mathrm{O}_{2}$
$100 \%$ ( 5 cães). A traquéia era seccionada completamente, nos segmentos iniciais, porção intratorácica, introduzindo-se, no coto distal, uma sonda endotraqueal com cuff, sem provocar interrupção prolongada da ventilação. Eletrodos de ECG eram suturados no pericárdio, para o controle contínuo do rítmo cardíaco durante a preservação.

Completados estes tempos cirúrgicos, iniciava-se a remoção, com bisturi elétrico, do conjunto coração-pulmão pelo seu plano de fixação no mediastino posterior sobre esôfago, coluna e diafragma. Apesar das manobras cirúrgicas, não se observaram modificações significativas nos parâmetros hemodinâmicos e ventilatórios, durante a retirada.

Já com o bloco fora do tórax, era feita uma revisão da hemostasia nas áreas de dissecção, sendo, após, imerso em soro fisiológico a $37^{\circ} \mathrm{C}$, no interior de um saco plástico, o qual, por sua vez, era acondicionado no interior de uma caixa de acrílico (Recipiente para Conservação e Transporte do Conjunto Cardiopulmonar), com o soro fisiológico.

Este recipiente é provido de resistências elétricas blindadas e duas tampas em níveis diferentes. A interna é provida de mecanismo de fixação do saco plástico e dos tubos e veda, completamente, o compartimento interno, mantendo-o estéril. A tampa externa é munida de orifício central para dar passagem aos tubos e limita uma antecâmera de segurança contra contaminação (Figura 2).

\section{RECIPIENTE PARA CONSERVACAAO E TRANSPORTE DO CONJUNTO CARDIOPULMONAR}

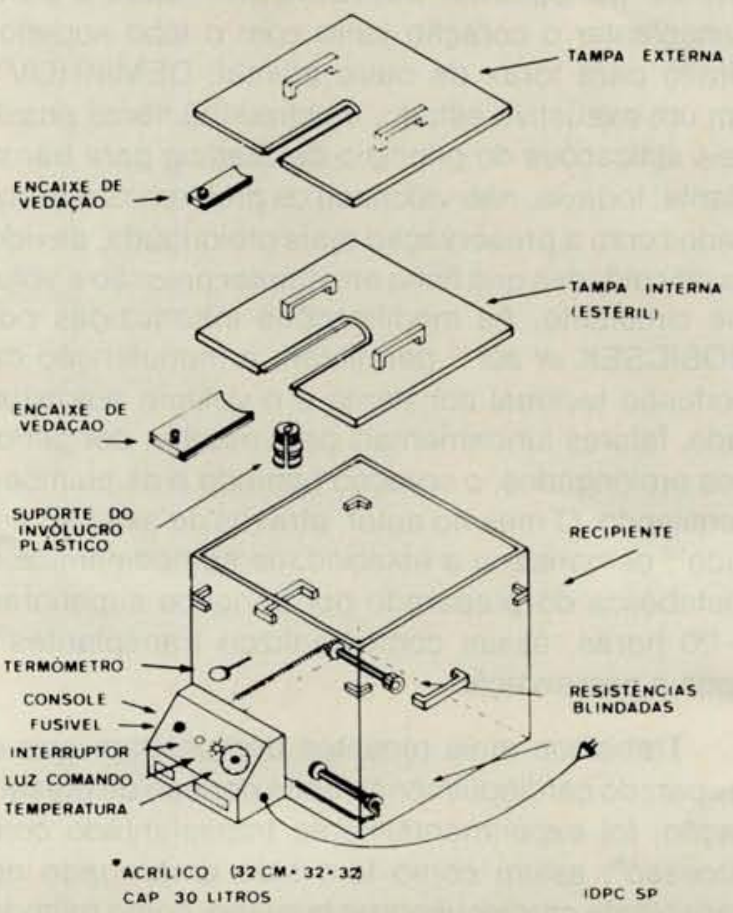

Fig. 2-Recipiente para Conservação e Transporte do Conjunto Cardiopulmonar (Esquema). 
Tem a capacidade de manter constante a temperatura dos líqüidos no seu interior, sem a geração de correntes elétricas no meio, acondicionar o preparado em condições estéreis e ser transportável. Realizavam-se colheitas periódicas de amostras para análise dos gases sangüíneos, hematócrito, sódio, potássio. O eletrocardiograma, assim como as pressões intraórtica (PAo) e intraventricular es- vando-se a parada dos batimentos e relaxamento cardíaco. Após a remoção das cânulas, o bloco era implantado no tórax do cão receptor, já preparado para este fim. Completadas as suturas, os batimentos cardíacos eram recuperados, reiniciando-se a ventilação do receptor com $\mathrm{O}_{2} \quad 100 \%$ e descontinuando a circulaçāo extracorpórea. Com níveis pressóricos estáveis, retiravam-se as cânu-

CD PREPARADO CARDIOPULMONAR N*14 (FEV 27, 1986)

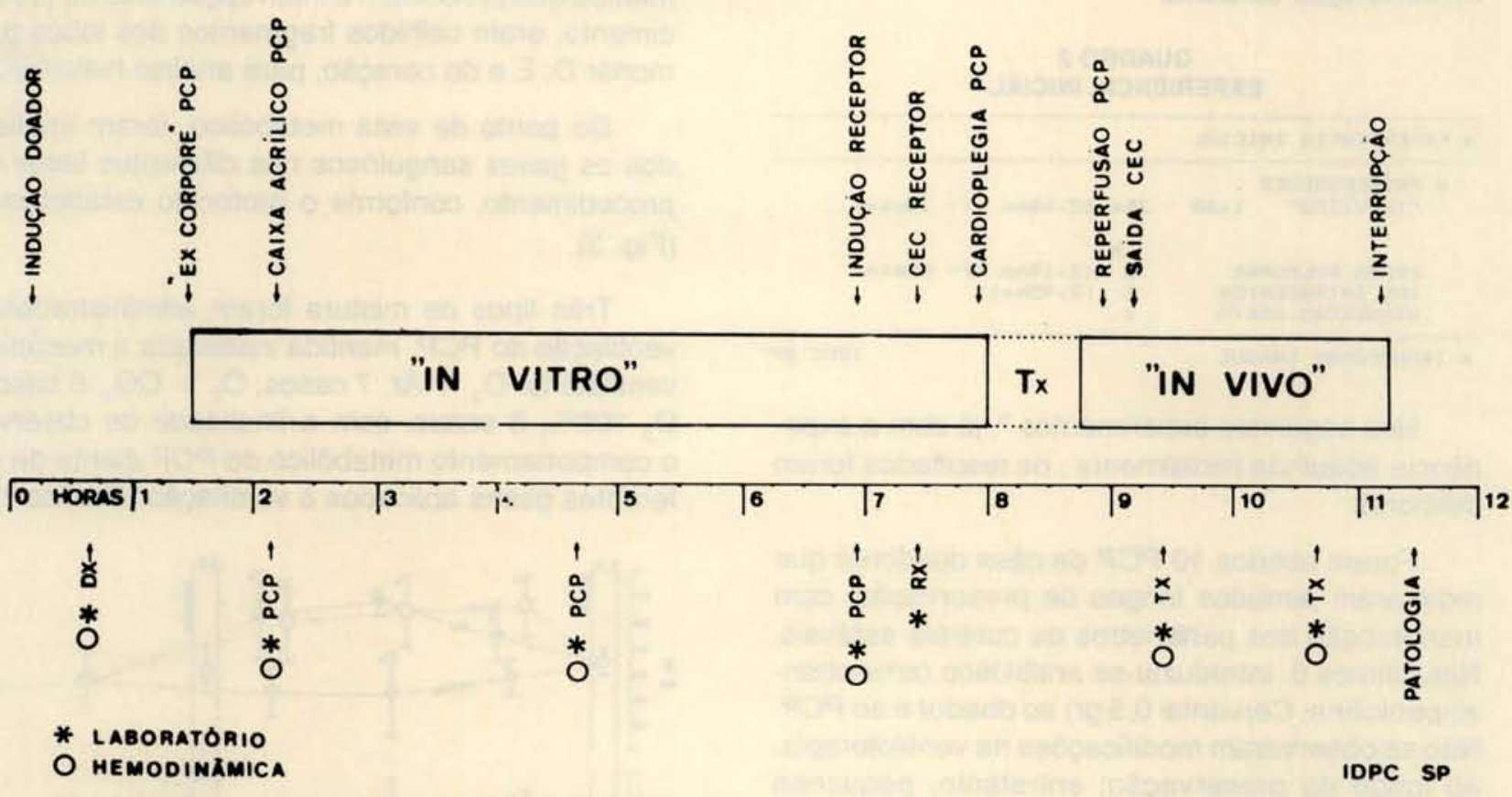

Fig. 3 - Protocolo do experimento. PCP n: 14 (Fev. 27, 1986).

querda (PVE), 1a derivada da pressão intraventricular (DP/DT), índice tempo-tensão (ITT) e trabalho cardiaco (TC) foram monitorizados constantemente, registrando-se os traçados conforme o protocolo (Figura 3). Fragmento de tecido pulmonar e cardiaco eram obtidos nos momentos que precediam a interrupção dos procedimentos, sendo remetidos, posteriormente, para análise histológica.

Dez preparados, após períodos variáveis de preservação, foram transplantados para cães com pesos semelhantes. Estes animais eram preparados de maneira convencional, com via de acesso por toracotomia mediana e suportados por circulação extracorpórea e hipotermia moderada $\left(32^{\circ} \mathrm{C}\right.$ esofágica). A técnica do transplante cardiopulmonar foi a descrita por JAMIESON et alii ${ }^{8}$. Imediatamente antes do início do implante, introduzia-se a solução cardioplégica a $4^{\circ} \mathrm{C}$ na raiz da aorta e soro gelado tópico, interrompendo-se a ventilação e a autoperfusão ex-corpore do preparado, obser- las do coração, neutralizava-se a heparina com a protamina e revisava-se a hemostasia. Nestas condiçōes o animal transplantado era mantido ainda por um período, colhendo-se amostras de sangue para o laboratório, registrando-se as curvas pressóricas e fragmentos do pulmão e do coração para análise histológica, próximo ao final do procedimento.

Foi feita avaliação estatística (T de Student) entre os dados iniciais (média c/desvio padrão) do doador e os obtidos ao longo do experimento sendo $p=>0,05$ estatísticamente significativo e $p=<$ 0,05 não significativo.

\section{RESULTADOS}

Os primeiros 8 experimentos foram realizados apenas para preservação e serviram para conhecer o procedimento e estabilizar a técnica operatória de obtenção do preparado cardiopulmonar (Quadro 2). O tempo em que o PCP ficou em autoperfusão 
ex-corpore foi ao redor de $(\mathrm{m}) 2,40$ horas, tendo ocorrido quadro de edema agudo pulmonar refratário ( 3 casos) com interrupção dos batimentos e dilatação cardíaca de causa indeterminada. Devido à perda de volume circulante ocorrida nos primeiros procedimentos, possivelmente devido a hemostasia inadequada, houve necessidade de transfundir sangue estocado em citrato colhido previamente. Em 1 caso, ocorreu insuficiēncia aórtica iatrogênica pela introdução excessiva da cânula $e$, em outro caso, houve um ferimento com dissecção logo acima do plano valvar aórtico, ocorrido no momento da canulação da aorta.

QUADRO 2

EXPERIÊNCIA INICIAL

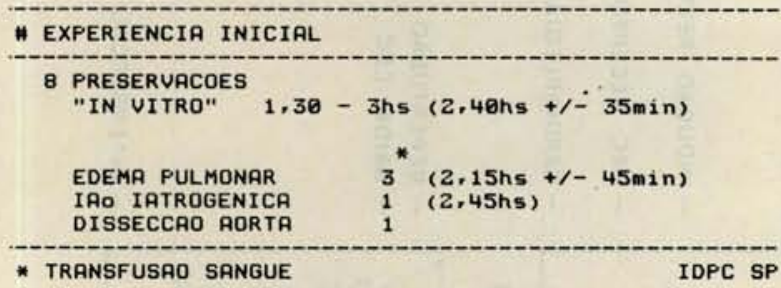

Nos seguintes experimentos ${ }^{5}$, já com a experiência adquirida inicialmente, os resultados foram melhores.

Foram obtidos 10 PCP de cães doadores que mostraram períodos longos de preservação, com manutenção dos parâmetros de controle estáveis. Nos últimos 6, introduziu-se antibiótico (aminobenzil-penicilina, Cervantal $0,5 \mathrm{gr}$ ) ao doador e ao PCP. Não se observaram modificações na ventiloterapia, ao longo da preservação; entretanto, pequenas áreas de atelectasia podiam ser vistas. A temperatura foi mantida constante dentro do Recipiente de Preservação ao redor de $38^{\circ} \mathrm{C}$ (normal para cães) (Quadro 3).

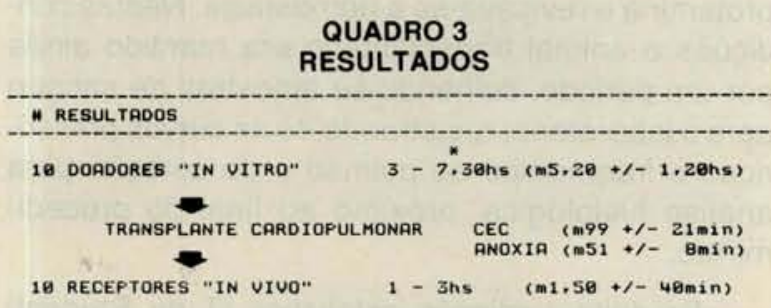

* ANTIBIOTICO IOPC SP

Dez receptores foram preparados, procurando-se manter a relação entre os pesos corporais dos animais. Introduziram-se pequenas modificaçōes na técnica cirúrgica ${ }^{8}$ e os transplantes foram realizados com tempo de CEC e anóxia idênticos a uma operação rotineira. Imediatamente antes das suturas, interrompia-se a autoperfusāo ex-corpore e a ventilação pulmonar, obtendo-se relaxamento cardiaco pela infusão de solução cardioplégica hipotérmica.
O tempo de circulação extracorpórea foi ao redor de 100 minutos, levando-se a temperatura do receptor a $32^{\circ} \mathrm{C}$. O tempo de anóxia, contado a partir da infusão da solução cardioplégica no PCP até a abertura da pinça da aorta no receptor, após completada a anastomose da aorta, oscilou ao redor dos 50 minutos, observando-se a recuperação espontânea ou por desfibrilação interna em ritmo sinusal e com parâmetros hemodinâmicos estáveis. Mantinha-se o controle hemodinâmico e laboratorial ainda por cerca de 3 horas, para se avaliar o comportamento dos órgãos implantados. Nos momentos que precediam a interrupção final do procedimento, eram colhidos fragmentos dos lobos pulmonar D, E e do coração, para análise histológica.

Do ponto de vista metabólico, foram analisados os gases sangüineos nas diferentes fases do procedimento, conforme o protocolo estabelecido (Fig. 3).

Três tipos de mistura foram administrados à ventilação do $P C P$, mantida inalterada a mecânica ventilatória: $\mathrm{O}_{2}+\mathrm{Ar}, 7$ casos; $\mathrm{O}_{2}+\mathrm{CO}_{2}, 6$ casos; $\mathrm{O}_{2} 100 \%, 5$ casos, com a finalidade de observar o comportamento metabólico do PCP diante de diferentes gases aplicados à ventilação (Gráfico 1).

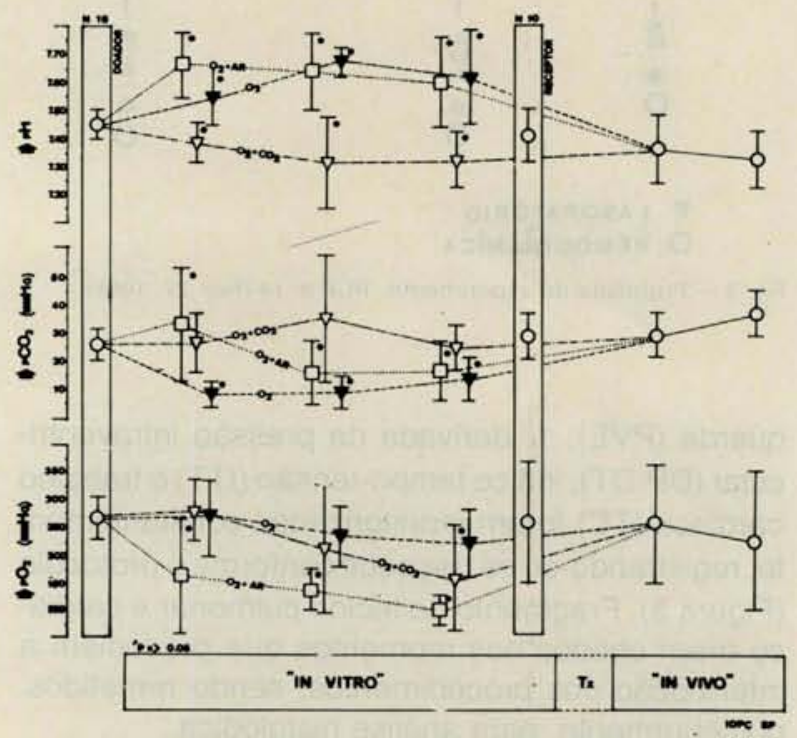

Gráf. 1 - Curvas de $\mathrm{pH}, \mathrm{pCO}_{2}, \mathrm{pO}_{2}$ com diferentes misturas $\mathrm{lO}_{2}+$ $\mathrm{CO}_{2}, \mathrm{O}_{2}+\mathrm{Ar}, \mathrm{O}_{2}$ ) administradas à ventilaçăo do $\mathrm{PCP}$ e após o transplante cardiopulmonar, com teste $T$ de Student.

Com a mistura $\mathrm{O}_{2}+$ Ar ocorreram níveis elevados do $\mathrm{pH}$ estatisticamente significativos $(\mathrm{p}=>$ 0,05 ), principalmente na fase inicial e intermediária da preservação, com pequena tendência a diminuição na fase inicial. Com $\mathrm{O}_{2} 100 \%$, observou-se uma curva idêntica à anterior, mas com tendência a aumentar $\mathrm{opH}$ mais na fase intermediária e final da preservação $(p=>0,05)$. Já com $\mathrm{O}_{2}+\mathrm{CO}_{2}$ $5 \%$, ocorreu o oposto, com o pH mostrando tendência a acidose leve, principalmente nas fases inter- 
mediária e final da preservaçāo. Comparando os dados da fase inicial com os restantes, visando analisar a evolução do $\mathrm{pH}$ durante a preservação, conclui-se que a curva do $\mathrm{pH}$, nas três misturas, foi estável, sem a ocorrência de eventos extraordinários $(p=<0,05)$. Após o transplante para o cão receptor, observou-se que $\mathrm{opH}$ em niveis normais $(p=<0,05)$ na primeira hora e com tendência a acidose leve $(p=>0,05)$ na segunda hora. Em relação ao $\mathrm{pCO}_{2}$ com a mistura $\mathrm{O}_{2}+$ Ar, observaram-se, na fase inicial, niveis próximos à normalidade, com tendência a baixar nas fases subseqüentes, sendo todos os valores da curva estatisticamente significativos ( $p=>0,05)$. A curva do $\mathrm{pCO}_{2}$ com $\mathrm{O}_{2}+\mathrm{CO}_{2} 5 \%$ foi a que melhor configuração apresentou, com seus valores nas diferentes fases da preservação estatisticamente não significantes $(p=>0,05)$. Em relação ao $\mathrm{O}_{2}$, observou-se uma tendência a queda acentuada do $\mathrm{pCO}_{2}$ durante toda preservaçāo, com seus valores sendo estatisticamente significativos $(p=>0,05)$. Comparando os dados da fase inicial com as restantes, visando analisar a evolução de $\mathrm{pCO}_{2}$ durante a preservação, conclui-se que a curva do $\mathrm{pCO}_{2}$, nas três misturas, foi estável, sem a ocorrência de eventos extraordinários ( $p=<0,05)$. Após o transplante para o cão receptor, observou-se o $\mathrm{pCO}_{2}$ em niveis normais $(\mathrm{p}=<0.05)$ na primeira avaliação, com tendência a se elevar $(p=>0,05)$ na segunda avaliação. Em relação ao $\mathrm{pO}_{2}$, sem comportamento com a mistura $\mathrm{O}_{2}+\mathrm{Ar}$, mostrou a ocorrência de níveis próximos à normalidade, com uma tendência a queda ao final da preservação, sendo seus valores estatisticamente significativos $(\mathrm{p}=>0,05)$. A curva do $\mathrm{pO}_{2}$ com $\mathrm{O}_{2}+\mathrm{CO}_{2}$ $5 \%$ demonstrou níveis mais elevados de oxigenação, com uma tendência a queda, à medida em que a preservação transcorreu, mas sempre em níveis adequados de oxigenação $(p=<0,05)$, exceto na fase final $(p=>0,05)$. Em relação ao $\mathrm{O}_{2}$, observam-se niveis elevados de oxigenação, durante a preservação $(p=<0,05)$. Comparando os dados da fase inicial com os restantes, visando analisar a evolução do $\mathrm{pCO}_{2}$ durante a preservação, conclui-se que a curva nas misturas $\mathrm{O}_{2}$ e $\mathrm{O}_{2}$ + Ar foi estável $(p=<0,05)$ e com $\mathrm{O}_{2}+\mathrm{CO}_{2}$ houve significância estatística ( $p=>0,05$ ), mas dentro de valores médios adequados. Após o transplante para o cão receptor, observou-se o $\mathrm{pO}_{2} \mathrm{em}$ niveis normais até $\mathrm{o}$ final do procedimento $(\mathrm{p}=$ $<0,05)$.

Analisando a curva do hematócrito (Gráfico 2), percebe-se tendência à queda dos seus valores, à medida em que a preservação transcorre, sendo seus valores, na fase intermediária e final, estatisticamente significativos $(p=>0,05)$. Após o transplante, o valor do hematócrito sobe, tendo em vista o acréscimo da volemia do cão receptor, entretanto, na última avaliaçāo, houve tendência a queda ( $p$ $=>0,05)$, devido, provavelmente, a dificuldades na coagulação, que, geralmente, estes animais apresentam, com conseqüente perda de volume. O sódio plasmático mostrou comportamento absolutamente estável ( $p=<0,05$ ), com variaçōes mínimas ao longo da preservação e após o transplante. Praticamente, a mesma evolução apresentou o potássio plasmático, cujas variações não foram estatisticamente significantes $(p=<0,05)$.

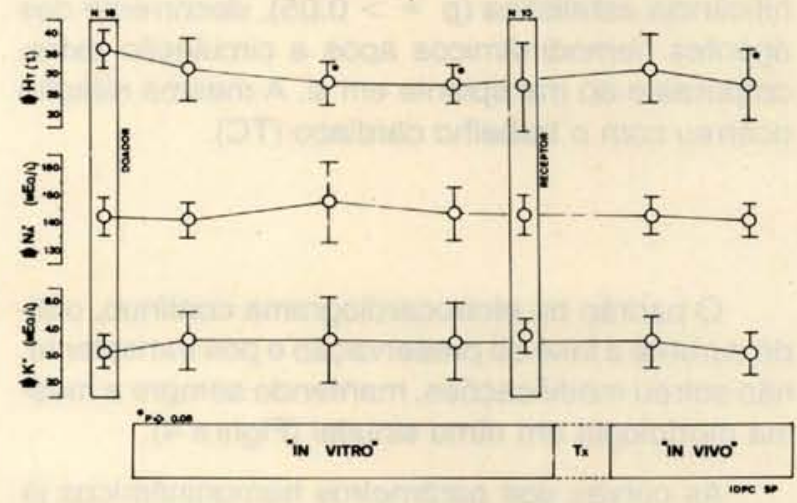

Gráf. 2 - Curvas de $\mathrm{pH}$, sódio, potássio obtidas durante todo o experimento incluindo doador, PCP e após o transplante cardiopulmonar com teste $T$ de Student.

No que diz respeito aos parâmetros hemodinâmicos, a freqüência cardiaca manteve, ao longo do experimento, incluindo preservação e pós-transplante, curva praticamente linear $(\mathrm{p}=<0,05)$ (Gráfico 3). A pressão intra-aórtica, tanto sistólica quanto diastólica, também se mostrou estável por todo o procedimento $(p=<0,05)$.

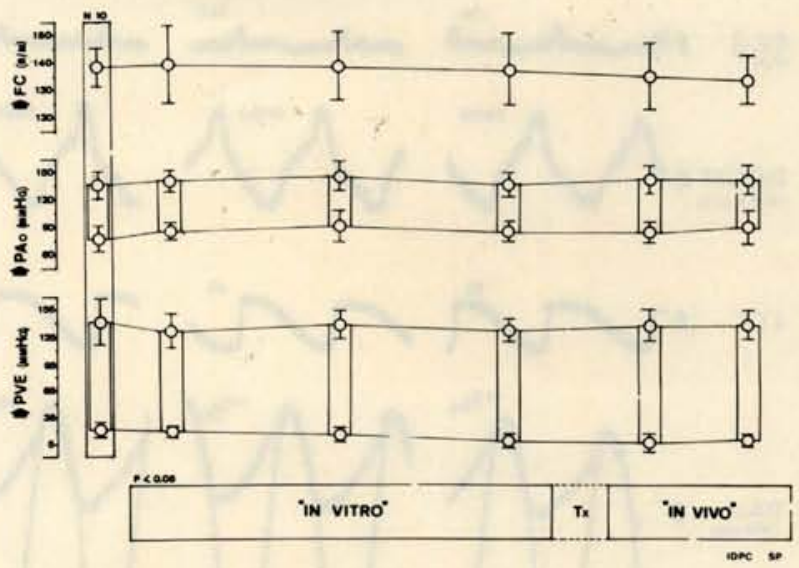

Graf. 3-Curvas da freqüencia cardiaca, pressão intra-aórtica e pressâo intraventricular obtidas durante todo o experimento incluindo doador, PCP e após o transplante cardiopulmonar com teste $\mathrm{T}$ de Student

Da mesma maneira, a pressão de ventrículo esquerdo, incluindo a sistólica e final diastólica, tambem mostrou estabilidade durante todo o procedimento. Não se observaram variações significa- 
tivas da média, ou do desvio padrão, da pressão final diastólica do ventrículo esquerdo.

Em relação à 1: derivada de pressão ventricular (DP/DT), analisada nos preparados que foram para o transplante cardiopulmonar, observa-se, também, uma evolução quase linear $(p=<0,05)$ durante a fase in vitro e in vivo (Gráfico 4). Quanto ao Índice Tempo Tensão (ITT), seus valores se mantiveram estáveis durante toda a preservação ( $p=<0,05$ ), enquanto que, após o transplante, 0 índice se mostrou ligeiramente elevado, com significância estatística ( $p=>0,05)$, decorrente dos agentes hemodinâmicos após a circulação extracorpórea e ao transplante em si. A mesma relação ocorreu com o trabalho cardiaco (TC).

O padrão do eletrocardiograma contínuo, obtido durante a fase de preservação e pós transplante, não sofreu modificações, mantendo sempre a mesma morfologia em rítmo sinusal (Figura 4).

As curvas dos parâmetros hemodinâmicos já analisadas aparecem na Figura 4, onde se observam morfologias idênticas em todas as fases do procedimento, inclusive no período pós transplante.

A avaliação histológica foi feita nos preparados
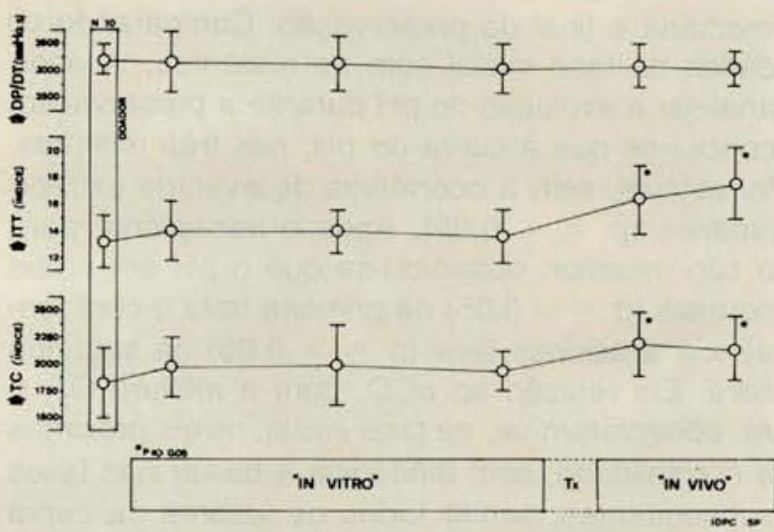

Gráf. $4-$ Curvas de 1: derivada da pressâo intraventricular (DP/DT) indice tempo-tensào (ITT) e trabalho cardiaco (TC) obtidas durante todo o experimento incluindo doador, PCP e após o transplante cardiopulmonar com teste $\mathrm{T}$ de Student.

que evoluíram para edema pulmonar ${ }^{23}$, na experiência inicial do trabalho, quanto naqueles em que a experiência foi levada até o final. Nos primeiros, o estudo histológico constatou sinais de lesão capilar pulmonar severa, traduzido morfologicamente por amplas áreas de edema e hemorragia intra-alveolares. Havia, também, lesões de vasos maiores, venosos e arteriais, caracterizadas por edema e hemorragia no espaço perivascular (Figura 5).

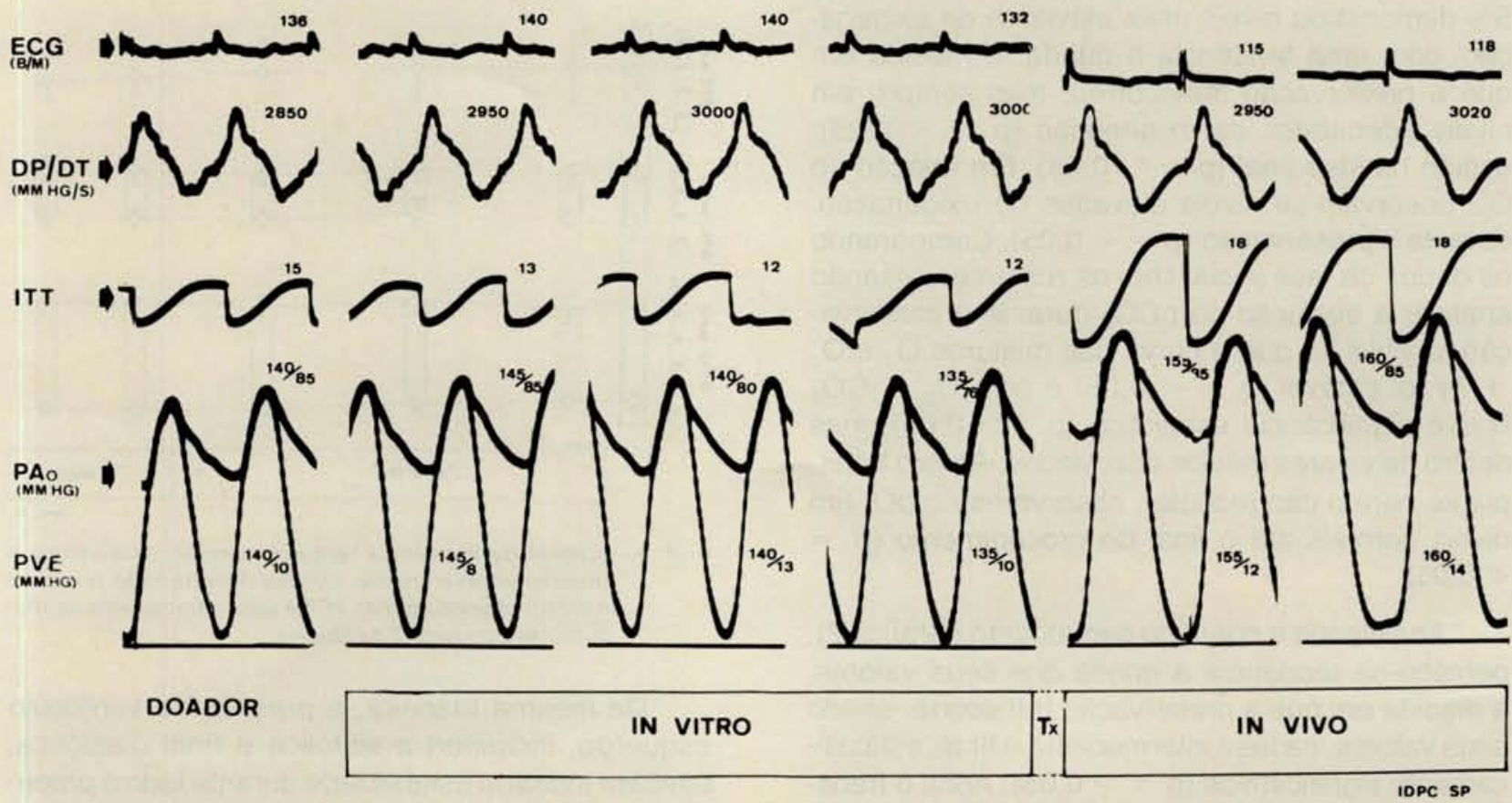

Fig. 4-Gráficos do eletrocardiograma (ECG), 1: derivada da pressão ventricular (DP/DT), indice tempo-tensáo (ITT), pressão intra-aórtica e pressão intraventricular obtidas nas diversas fases do experimento. 


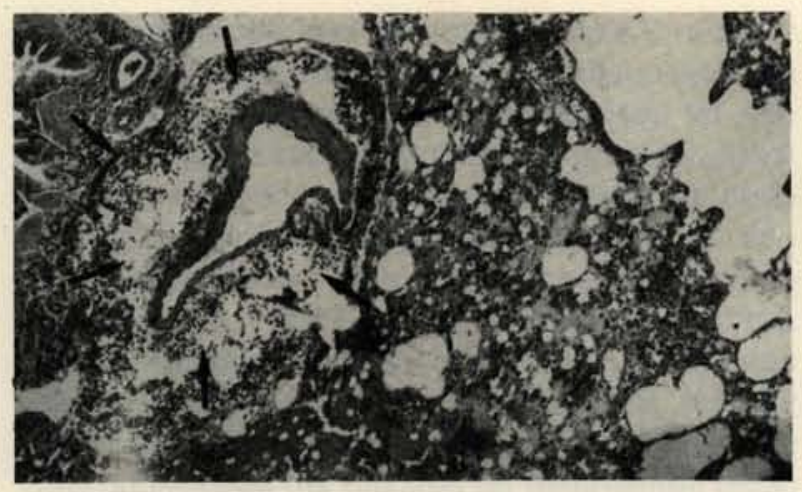

Fig. 5 - Pulmâo com intenso edema e hemorragia alveolares em torno de artérias (setas). HE 63x. PCP n: 5 (Set. 12, 1985), In vitro $90 \mathrm{~min}$ seguido de edema pulmonar

Os vasos do coração também se mostravam atingidos, de tal forma que estabeleceram focos hemorrágicos perivasculares em região epicárdica e no miocárdio. No segundo grupo, foi evidente a melhora do quadro histológico pulmonar, onde se verificaram apenas focos irrelevantes de extravazamento de hemácias e líqüido para o espaço alveolar; persiste o edema perivascular em veias e artérias, porém em grau menor que aquele observado no grupo anterior e sem hemorragia (Figura $6)$.

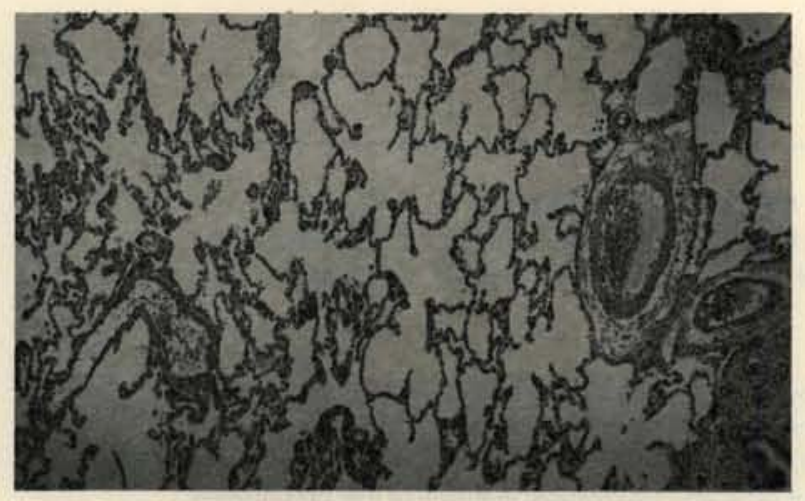

Fig. 6 - Pulmâo com septos e alvéolos conservados. Leve edema perivascular. HE 63x. PCP n: 9 (Nov. 06, 1985) In vitro 4 horas; In vivo 3 horas.

Marginação leucocitária em capilares e pequenos vasos é evidenciada naqueles preparados oriundos das experiências mais prolongadas. Os septos alveolares são, em geral, bem conservados, tendo-se observado rotura alveolar um pouco mais intensa em apenas 1 caso (preparado n: 13). Esse pulmão, contudo, apresentava antracose importante e inflamação crônica peribrônquica. Todavia, a alteração parece não ter interferido com a função do transplante, pois este é um dos preparados em que a experiência foi duradoura (in vitro $51 / 2 \mathrm{~h}$ In VIVo 1 1/2 h). A preservação miocárdica é ainda melhor que a pulmonar, do ponto de vista da microscopia óptica. Há edema intersticial discreto e

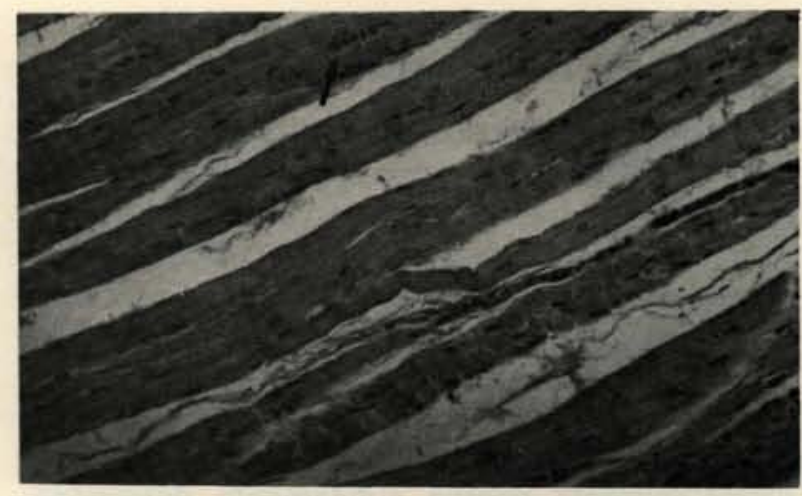

Fig. 7 - Miocárdio com edema intersticial e preservaçăo de fibras. Leve marginação leucocitária (seta). HE $-160 x$. PCP n: 9 (Nov. $06,1985)$ In vitro 4 horas; in vivo 3 horas.

ocasional necrose de células isoladas (Figura 7).

Também aqui se verifica marginação leucocitária, sempre em intensidade menor que nos pulmões, sem outros sinais de lesão vascular.

\section{COMENTÁRIOS}

Inúmeros trabalhos têm sido realizados visando ao estudo da preservação do músculo cardíaco por períodos prolongados em hipotermia ${ }^{4,14}$, com a finalidade precípua de manter sua viabilidade para transplante. Por outro lado, já se constitui rotina nos Serviços que praticam transplantes cardíacos, a busca à distância do órgão ${ }^{23}$ preservado por cardioplegia e hipotermia, por período ao redor de 3 horas de anóxia, com resultados satisfatórios. Entretanto, este tipo de procedimento tem suas limitações, pois, transcorrido este espaço de tempo, sucedem-se alteraçōes no órgão que podem vir a comprometer sua função após o implante, principalmente nos casos onde ocorrem níveis moderadamente elevados de pressão na artéria pulmonar.

Com o tecido pulmonar, estes aspectos são ainda mais críticos ${ }^{7}$, pois, desafortunadamente, a hipotermia, por si, mostou ser um método inconsistente para preservar o pulmão por períodos prolongados.

Estes aspectos concorrem, até certo ponto, na limitação do transplante cardíaco e, em definitivo, no cardiopulmonar, no que diz respeito à preservação por período maior, conseqüentemente na busca de órgãos à distância.

A primeira tentativa de prolongar o tempo útil do preparado cardiopulmonar foi feita por SEN et $a{ }^{2 i}{ }^{21}$, em 1951. Vários trabalhos foram desenvolvidos $^{5.12}$, no sentido de prolongar as funçōes do coração e dos pulmōes além de 1 hora, mas foram 
infrutiferas, cuja causa principal foi o desequilíbrio do volume de sangue circulante.

Após as modificações introduzidas no PCP por ROBICSEK et alii ${ }^{19}$ tornando-o um sistema autoajustável, é que foi possível a manutenção do conjunto por período prolongado em condiçōes fisiológicas, abrindo, assim, a perspectiva de aplicação do PCP no campo da preservação de órgãos para fim de transplante. Este mesmo autor ${ }^{18}$ logrou conseguir preservação acima de 8 horas, observando que, proporcional ao tempo decorrido e sem uma causa aparente, ocorria, subitamente, deteriorização dos batimentos cardíacos, seguida de dilatação das cavidades e parada. YAMADA ${ }^{24}$ demonstrou que, com a aplicação de esteróide (dexametasona), a viabilidade do preparado se prolonga de 15 a 24 horas, provavelmente devido à estabilização da membrana preservando a integridade celular do miocárdio, pulmonar e sangüínea.

A análise dos parâmetros obtidos no presente trabalho consubstanciam os trabalhos previamente realizados com o PCP. Foram obtidas preservações acima de 6 horas, onde as funçōes cardíacas e pulmonares mostraram extraordinária estabilidade e adequação do funcionamento no transplante para outro animal.
Em 3 experimentos na fase inicial ao estudo, ocorreu quadro de edema pulmonar, cuja causa não foi absolutamente determinada; todavia, em todos, foram aplicadas transfusões de sangue estocado em citrato, eliminando-se este procedimento nas experiências subseqüentes. Outro fator que chamou a atenção foi a maior longevidade após a introdução de antibiótico ao PCP ${ }^{17}$. Estes fatores também causaram melhora evidente na análise histológica. Com aumento do tempo de preservaçāo, surgiram focos de marginação leucocitária com aspecto semelhante ao descrito em associação com circulação extracorpórea ${ }^{15}$. Não sabemos, contudo, se estão presentes as mesmas alterações vasculares e leucocitárias dos pulmões submetidos a circulação extracorpórea, uma vez que não foi realizada avaliação ultra-estrutural, nesta fase da pesquisa. A hemorragia perivascular dos pulmões se assemelha a aspectos descritos na rejeição de transplantes pulmonares ${ }^{23}$. Contudo, nossa fase de avaliação morfológica é muito precoce para que se tenham estabelecido os fenômenos de rejeiçāo e, também, não se verificam lesões miocárdicas consistentes, com este diagnóstico ${ }^{2,3}$. Este dado é relevante, uma vez que a rejeição pulmonar não parece ocorrer sem rejeição cardiaca concomitante 22

DINKHUYSEN, J. J.; SOUZA, L. C. B.; CHACCUR, P.; NEGER, F; ARNONI, A. S.; PAES NETO, F.; CONFORTI, C.A.; BISCEGLI, J. F.; ZAMORANO, M. M. B.; LEONE, E. C. H.; MANRIQUE, R.; PAULISTA, P. P.: JATENE, A. D. - Heart and lung experimental preservatnio. Rev. Bras. Cir. Cardiovasc., 1(1): 20-31, 1986.

ABSTRACT: A simple method is presented which proved to be effective for maintaining the heart and lungs viable and functioning in good hemodynamic and metabolic conditions outside of the body, for a period of up to 7 hours. After this, the heart-lung preparation is transplanted to another animal which maintains good parameters also for 3 hours. The hemodynamic, biochemical and histological features of this preparation are presented. In conclusion. preservation of a heart-lung allograft in a dynamic state provides a means to transport donor organs over long distances, and appears to be suitable to serve as a graft for heart or heart-lung transplantation.

DESCRIPTORS: heart-lung preparation; heart-lung preservation, experimental; heart transplantation.

\section{REFERÊNCIAS BIBLIOGRÁFICAS}

1 BARNARD, C. N. - The operation. A human heart transplantation: an interin report of the successful operation performed at Groote Shurr Hospital. Cape Town. South Africa, S. Afr. Med. J, 41: 1271-1274, 1967

BILLINGHAM, M. E. - Diagnosis of cardiac rejection by endomyocardial biopsy. Heart Transplant., 1: 25 1982.

3 CAVES, P. K.: STINSON, E. B.; BILLINGHAM, M. E.: SHUMWAY, N. E. - Serial transvenous biopsy of the transplanted human heart: improved management of acute rejection episodes. Lancet, 1: 821-826, 1974.
4 COPELAND, J. G.; JONES, M.; SPRAGG, R.; STINSON, E. B. - In vitro preservation of canine hearts for 24 to 48 hours followed by successful orthotopic transplantation. Ann. Surg., 178: 687-692, 1973.

5 DEMIKHOV, V.P. - Experimental transplantation of vital organ. New York, Consultant Bureau, 1962, p. 60.

6 GOLDING, C. R.; STEWART, R. W.; MORIMOTO, H.; NOSÉ, Y.; LOOP, F. D. - Ansuccessful acute heart lung transplantation after six hours preservation. Heart Transplant., 4: 252, 1985. 
7 HAVERICH, A.; SCOTT, W. C.; JAMIESON, S. W. Twenty years of lung preservation: a review. Heart Transplant., 4: 234, 1985

8 JAMIESON, S. W.; STINSON, E. B.; OYER, P. E.; BALDWIN, J. C.; SHUMWAY, N.E. - Operative technique for heart-lung transplantation J. Thorac. Cardiovasc. Surg., 87: 930-935, 1984.

9 KNOWLTON, F. P. \& STARLING, E. H. - The influence of variation in temperature and blood-pressure on the performance of the isolated mammalian heart. $A m$. J. Physiol., 44: 206, 1912.

10 LADOWSKI, J. S.; KAPELANSKY, D. P.; TEODORI, M. F.; STEVENSON, W. C.; HARDESTY, R. L.; GRIFFITH, B. P. - Use of autoperfusion for distant procurement of heart-lung allografts. Heart Transplant., 4 $330-333,1985$

11 MARTIN, H. N. - The direct influence of gradual variations of temperature upon the rate of beat of the dog's heart. Philos. Trans. R. Soc. Lond., 174:663, 1883.

12 MATEJICEK, E. - Transplantation organs. Transplant. Bull., 3: 4, 1956-1957.

13 PATTERSON, S. W. \& STARLING, E. H. - On the mechanical factors which determine the output of the ventricles. Am. J. Physiol., 48: 357, 1914.

14 PROCTOR, E.; MATTHEWS, G.; ARCHIBALD, J. - Acute orthotopic transplantation of hearts stored for 72 hours. Thorax, 26: 99-102, 1971.

15 RATLIFF, N. B.; YOUNG Jr., G.; HACKEL, D. B.; MIKAT E.; WILSON, J. W. - Pulmonary injury secondary to extracorporeal circulation : an ultrastructural study. J. Thorac. Cardiovasc. Surg., 65: 425-432, 1973.

16 REITZ, B. A.; WALLWORK, J. L.; HUNT, S. A.; PENNOCK J. L.: BILLINGHAM, M. E.; OYER, P. E.; STINSON E. B.; SHUMWAY, N. E. - Heart-lung transplantation: successful therapy for patients with pulmonary vascular disease. N. Engl. J. Med., 306: 537-564, 1982.

17 ROBICSEK, F.; DUNCAN, G. D.; DENYER, M.; MASTERS, T. N. - Preservation of donor hearts by an Autoperfusing Heart-Lung Preparation (AHLP). Heart Transplant., 4 (Supl. 1): 125, 1985.

18 ROBICSEK, F.: PRUITT, J. R.; SANGER, P. W.; DAUGHERTY, H. K.; MOORE, M.; BAGBY, E. - The maintenance of function of the donor heart in the extracorporeal stage and during transplantation. Ann. Thorac. Surg., 6: 330-342, 1968

19 ROBICSEK, F.; SANGER, P. W.; TAYLOR, F. H. - Simple method of keeping the heart "alive" and functioning outside of the body for prolonged periods. Surgery, 53: $525-530,1963$

ROBICSEK, F.; TAM, W.; DAUGHERTY, H. K.; ROBISCOK, L. K. - The Stabilized Autoperfusing Heart Lung Preparation as a vehicle for extracorporeal preservation. Transplant. Proc., 1: 834, 1968

SEN, P. K.; SHAH, C. B.; SATOSKAR, R. S. - Studies on isolated Heart-Lung Preparation in the hypotermic animal. J. Intern. Coll. Surg., 26: 32-37, 1956 LENKOPF, F. P. - Lung transplantation. Heart Trans plant., 2: 155-164, 1983.
23 WATSON, D. C.; REITZ, B. A.; BAUMGARTNER, W. A. RANEY, A. A.; OYER, P. E.; STINSON, E. B.; SHUMWAY, N. E. - Distant heart procurement for transplantation. Surgery, 86: 56-69, 1979.

24 YAMADA, T.; BOSHER Jr., L. H.; RICHARDSON, G. M - Observations on the Autoperfusing Heart - Lung Preparation. Trans. Amer. Soc. Artif. Intern. Organs., 11: 192-196, 1965

\section{Discussão}

DR. DELMONT BITTENCOURT

São Paulo, SP

O trabalho "Preparado Cardiopulmonar" realça o interesse atual pelos transplantes de órgãos, especialmente agora, após a introdução de métodos mais eficientes de combate à rejeição.

O transplante do bloco coração-pulmão é uma grande empreitaḑa cirúrgica e necessita de táticas especiais. Até o presente, os grupos cirúrgicos que têm realizado este tipo de transplante o fazem com o doador no mesmo centro cirúrgico onde está o receptor. Isto porque o transporte do pulmão em bloco traz problemas após uma hora, mesmo com hipotermia.

O "Preparado Cardiopulmonar" apresentado pelo Dr. Jarbas é elegante e, provavelmente, permitirá o transporte e o transplante até 4 ou 5 horas após a colheita. Os fundamentos desse preparado foram estudados pelo grupo de Pittsburgh, conforme a apresentação de Ladowski, em 1985.

No Instituto do Coração da FMUSP, está, igualmente, em andamento a experimentação no sentido de preservar o bloco coração-pulmão, em trabalhos realizados na Cirurgia Experimental, pelo grupo do Dr. Ronaldo Fontes. Este grupo está realizando uma etapa de pesquisas, tendo estudado um grupo de seis blocos coração-pulmão obtidos de cães e conservados por período de 2 a 8 horas. Nessas preparações, têm sido feitas biópsias do ventrículo direito e dos pulmões cada 2 horas. Além disso, são controladas a gasometria, os eletrólitos e a hemoglobina, a glicemia e diversos parâmetros hemodinâmicos (pressão de $\mathrm{AD}$, pressão arterial média, pressōes sistólica, diastólica e média do VE, pressão de capilar pulmonar, débito cardíaco por fluxômetro), mantendo o preparado em normotermia, a $37^{\circ} \mathrm{C}$. Nessa etapa de pesquisas, as biópsias deterioram o preparado, produzem hematomas, alteram a hemodinâmica, sobrevindo edema agudo pulmonar. Nos blocos transplantados para outros cães ainda são freqüentes as áreas de atelectasias. 
Todos os esforços para aperfeiçoar esses preparados são importantes, pois é extremamente dificil conseguir o transporte de doador para outro hospital, por vezes distante, especialmente pela resistência apresentada pelos familiares do doador.

DR. DANTON R. ROCHA LOURES

Curitiba, $P R$

Em nome do grupo do Hospital Evangélico de Curitiba, atualmente envolvido nas pesquisas para os transplantes cardíaco e cardiopulmonar, quero parabenizar Dr. Jarbas J. Dinkhuysen e o grupo do Instituto Dante Pazzanese de Cardiologia, pelo excelente trabalho apresentado.

A preservação do coração isolado para transplantes em locais distantes se tem valido da hipotermia e de soluções cristalóides geladas, permitindo o seu emprego até 3 horas após a explantação cardíaca.

Este método de preservação clássico para o coração apresentou resultados menos favoráveis para os pulmões. O leito capilar e o septo alvéolocapilar são mais susceptiveis às injúrias isquêmicas que as estruturas de outros órgãos. Qualquer dano na rede capilar resulta em edema, rotura de membrana alvéolo-capilar e alteração funcional. Motivados por esies conhecimentos, foram testados outros métodos de preservação pulmonar. Atualmente, soluções como as de Collins e Sachs modificadas e a manutenção dos pulmões insuflados têm sido recomendadas por diversos Serviços.

Desde o primeiro transplante pulmonar isolado, realizado por Hardy, em 1963, os resultados foram desfavoráveis, revelando, neste período de 23 anos, uma sobrevivência quase sempre inferior a 1 ano.

A viabilidade pulmonar tem-se tornado maior após a utilização nos transplantes em bloco com o coração. O grupo de Stanford tem publicado sobrevida superior a 3 anos com esta técnica.

O trabalho experimental apresentado pelo $\mathrm{Dr}$. Jarbas e colaboradores utiliza a preservação cardiopulmonar em bloco e em condições fisiológicas. A metodologia deste estudo tem sido aplicada também pelo grupo de Pittsburgh e sua viabilidade se fundamenta em 3 pontos:

a) Preservação fisiológica do coração e pulmōes

b) Ausência aparente de insultos isquêmicos após 2-5 horas c) Transporte exclusivo do coração e pulmões

Gostaria, no entretanto, de perguntar:

1) Qual a possibilidade de uma fibrilação ventricular durante o transporte e como poderia ser contornada?

2) A presença de ventilação artificial pode aumentar o risco de infecção?

3) Por que não empregar uma metodologia mais simplificada, como a defendida pelo grupo de Stanford, preservando o coração com hipotermia e solução cardioplégica, e os pulmões com a circulação de soluōes tipo Collins e Sachs e mantendo os pulmões insuflados?

\section{DR. DINKHUYSEN ( Encerrando)}

Agradeço os comentários feitos pelos Doutores Bittencourt e. Loures. Já há algum tempo, a convite do Professor Adib Jatene, tivemos a oportunidade de realizar, no INCOR, uma destas preparações e, nessa ocasiâo, sentimos grande interesse por parte dos cirurgiōes e pesquisadores que lá trabalham. De acordo com o comentário feito pelo Dr. Bittencourt, o INCOR já está realizando este experimento em toda sua plenitude, inclusive obtendo biópsias retiradas do ventrículo direito e dos pulmões, o que, sem dúvida, acrescentará mais informações sobre sua viabilidade. A presença de áreas de atelectasias nos blocos transplantados para cães recipientes não constituiu dificuldade, nos nossos experimentos, pois desapareceram após alguns ciclos respiratórios com um volume corrente maior, semelhante a suspiros, e não foram causas de alteraçōes nos índices de oxigenação e mecânica ventilatória. Dr. Loures comenta a dificuldade na preservação do tecido pulmonar, dada sua susceptibilidade à isquemia e às modificações que ocorrem a curto prazo, no leito capilar e septo alvéolo-capilar, notadamente frente aos métodos comumente empregados para a preservação do músculo cardíaco, com anóxia e hipotermia. É neste ponto que reside o fundamento do nosso trabaIho, pois preconiza preservação em condições fisiológicas, tanto do coração, quanto dos pulmões, por períodos maiores. Recentemente, foi publicado, no Heart Transplantation, pelo Dr. Jamieson, da Universidade de Stanford, um extenso artigo sobre preservação pulmonar, e sua conclusão é que os pulmões não suportam períodos mais longos de anóxia, apesar do uso de soluçōes hipotérmicas, provocando importantes restrições logísticas nos programas de transplante cardiopulmonar, relativas à obtenção dos órgãos, obrigando a presença 
do doador e receptor lado a lado. Foi em Pittsburgh (USA) que tivemos a oportunidade de conhecer o preparado, por ocasião de um transplante cardiopulmonar realizado em humano, motivo pelo qual julgamos oportuno conhecer e nos familiarizar com esta técnica. Um dos aspectos que mais chamam a atenção no PCP é sua estabilidade após a instituição do circuito de autoperfusão, tanto durante a retirada do bloco coração e pulmão do tórax, quanto após acondicionado na caixa de acrílico. Para tanto, é evidente a necessidade de parâmetros metabólicos e hemodinâmicos sem desvios grosseiros. Dentro destas condiçōes, em um período até ao redor de 5 a 6 horas, julgamos pouco provável a ocorrência de fibrilação ventricular. Cóntudo, se tal manifestação viésse a ocorrer, o conjunto não se prestaria para fins de transplante e qualquer maneira de prevenir esta complicação fica difícil de conceber, a não ser com conjecturas. A presença de agentes potencialmente causadores de infecção é normal na via aérea, pois está em intimo contato com o ar ambiente. $\mathrm{O}$ fato de aplicarmos, ou não, ventilação artificial por períodos curtos não estabelece condiçōes precípuas a infecção. O fundamento deste sistema de preservação situa-se diametralmente oposto ao preconizado pelo grupo de Stanford, que emprega hipotermia e anóxia. É nossa impressão que o método aqui descrito, apesar de mais complicado, parece menos agressivo aos tecidos, pois mantém íntegros o metabolismo e a fisiologia dos órgãos e, talvez por isto, sua durabilidade seja maior. Como comentário final, gostaria de ressaltar a versatilidade do PCP no ensino da fisiologia cardiopulmonar e na pesquisa nos mais variados campos da área médica. Obrigado. 